\title{
Geographic Variation in Out-of-Pocket Expenditures of Elderly Medicare Beneficiaries
}

\author{
Lena M. Chen, MD, MS, ${ }^{a, b, c, d}$ Edward C. Norton, PhD, ${ }^{b, e, f, g}$ Kenneth M. Langa, MD, PhD, ${ }^{a, c, d, h}$ \\ Sidney Le, BA, ${ }^{i}$ and Arnold M. Epstein, MD, $M A^{i, j}$
}

\begin{abstract}
OBJECTIVES: To examine whether out-of-pocket expenditures (OOPEs) exhibit the same geographic variation as Medicare claims, given wide variation in the costs of U.S. health care, but no information on how that translates into OOPEs or financial burden for older Americans.

DESIGN: Retrospective cohort study.
\end{abstract}

SETTING: Data from the Health and Retirement Study linked to Medicare claims.

PARTICIPANTS: A nationally representative cohort of 4,657 noninstitutionalized, community-dwelling, fee-forservice elderly Medicare beneficiaries interviewed in 2006 and 2008.

MEASUREMENTS: The primary predictor was per capita Medicare spending quintile according to hospital referral region. The primary outcome was a self-reported, validated measure of annual OOPEs excluding premiums.

RESULTS: Mean and median adjusted per capita Medicare payments were $\$ 5,916$ and $\$ 2,635$, respectively; mean and median adjusted OOPEs were $\$ 1,525$ and $\$ 779$, respectively. Adjusted median Medicare payments were $\$ 3,474$ in the highest cost quintile and $\$ 1,942$ in the lowest cost quintile (ratio $1.79, P<.001$ for difference).

From the ${ }^{\mathrm{a} D i v i s i o n}$ of General Medicine, Department of Internal Medicine, School of Medicine, University of Michigan, ${ }^{\mathrm{b}}$ Center for Healthcare Outcomes and Policy, University of Michigan, 'Institute for Healthcare Policy and Innovation, University of Michigan, ${ }^{\mathrm{d}}$ Veterans Affairs Ann Arbor Healthcare System, ${ }^{e}$ Department of Health

Management and Policy, School of Public Health, University of Michigan, ${ }_{\mathrm{f}}^{\mathrm{f}}$ Department of Economics, University of Michigan, Ann Arbor, Michigan; ${ }^{g}$ National Bureau of Economic Research, Cambridge, Massachusetts; ${ }^{\mathrm{h}}$ Institute for Social Research, University of Michigan, Ann Arbor, Michigan; ${ }^{\mathrm{i}}$ Department of Health Policy and Management, Harvard School of Public Health, and ${ }^{j}$ Division of General Internal Medicine, Brigham and Women's Hospital and Harvard Medical School, Boston, Massachusetts.

The abstract was presented as a poster at the AcademyHealth Annual Research Meeting, June 25, 2012, and as a plenary talk at the Society of General Internal Medicine Annual Meeting, May 12, 2012.

Address correspondence to Lena M. Chen, Division of General Medicine University of Michigan, North Campus Research Complex, 2800 Plymouth Road, Building 16, Room 407E, Ann Arbor, MI 48109.

E-mail: lenac@umich.edu

DOI: 10.1111 /jgs. 12834
In contrast, adjusted median OOPEs were not higher in the highest than in the lowest Medicare cost quintile ( $\$ 795$ vs $\$ 764$ for a $\mathrm{Q} 5: \mathrm{Q} 1$ ratio of $1.04, P=.42$ ). The Q5:Q1 ratio was 1.48 for adjusted mean Medicare payments and 1.04 for adjusted mean OOPEs (both $P<.001$ ).

CONCLUSION: Medicare payments vary widely between high- and low-cost regions, but OOPEs do not.

J Am Geriatr Soc 62:1097-1104, 2014.

Key words: out-of-pocket expenditures; geographic variation; Medicare

$T$ he use and costs of U.S. health care vary widely between geographic regions, ${ }^{1,2}$ and some policy-makers believe that targeting high-cost areas could reduce spending without harming quality. Wage rate-standardized per capita Medicare payments vary more than twofold in different regions of the country, ${ }^{3}$ but it is unclear whether higher-cost regions reap commensurate benefits. Most prior work has shown that higher-cost regions do not produce better results in a variety of areas, including access, mortality, process measures of quality, and patient satisfaction, ${ }^{1,2,4}$ although debate is ongoing. ${ }^{5-7}$ Despite the lack of apparent benefit associated with higher costs, public support to reduce spending in high-cost areas has been slow to materialize.

Although the effect of geographic variation in costs of care on quality of care is important, the direct financial consequences of healthcare choices also concern patients. Some researchers have found that more than half of all personal bankruptcies in 2007 were attributable to medical illness, with income loss and medical bills as contributors to these bankruptcies. ${ }^{8}$ Others have documented substantial out-of-pocket medical expenditures (OOPEs) for Americans and a growth in the proportion facing burdensome OOPEs over time. ${ }^{9-12}$ In spite of these findings, no research has examined to what extent geographic variation in costs of care directly affects patient finances and whether there is the same geographic variation in OOPEs. 
Therefore, the current study sought to explore the association between geographic variation in costs of care and patients' financial burden from healthcare costs. For one relatively homogeneous and important group (community-dwelling, noninstitutionalized Medicare beneficiaries), two questions were addressed. First, what are the characteristics associated with higher OOPEs? Second, after controlling for these characteristics, how much do OOPEs differ between high- and low-cost regions, and how does this compare with geographic variation in Medicare payments?

\section{METHODS}

\section{Conceptual Model}

It was hypothesized that Medicare payments would affect OOPEs because of co-insurance, copayments, and deductibles. It is likely that several factors affect Medicare payments and OOPEs in a similar direction, including factors such as sex (female sex plausibly being associated with higher Medicare payments and thus higher OOPEs) and self-reported health (poor health plausibly being associated with higher Medicare payments and thus higher OOPEs).

It was hypothesized that several factors would affect OOPEs differently than they affect use, including net worth, income, and supplemental insurance. For example, those with higher net worth and income may use services that are paid solely out of pocket (not covered by Medicare), and thus their OOPEs may not correlate with their costs of care (defined as Medicare payments).

For those with supplemental insurance, higher Medicare spending also may not be associated with higher OOPEs. Prior work has found that supplemental insurance for Medicare beneficiaries is associated with higher Medicare Part $\mathrm{A}$ and $\mathrm{B}$ spending ${ }^{13}$ and a faster rise in total Medicare spending, ${ }^{14}$ but nearly $60 \%$ Medicare beneficiaries with Medigap have first-dollar coverage that covers all co-insurance and deductibles for Part A and B spending. ${ }^{15}$

\section{Data Sources}

The Health and Retirement Study (HRS) is an ongoing, nationally representative, longitudinal survey of more than 26,000 Americans aged 50 and older. Since the study's initiation in 1992, respondents have been interviewed every 2 years on a number of topics, including their wealth and health. Overall response rates for the 2006 and 2008 interviews were $89 \%$ and $88 \% .{ }^{16}$ Medicare claims data supplement survey data.

The most-recent Medicare claims data linked to the HRS that could be obtained (2006 and 2007) were used to determine annual Medicare spending for those in the cohort. The 2008 HRS was used to obtain self-reported OOPEs and decisions to cut back on medications due to costs in the 2 years before the 2008 interview (2006-07). The 2006 HRS provided information on baseline demographic characteristics, including the ZIP code used to assign each person in the cohort to a hospital referral region (HRR). It also provided data on the self-reported predicted probability that an individual would use up all of his or her savings in the next 5 years to pay for health care.

\section{Study Population}

The goal was to identify a cohort of noninstitutionalized, fee-for-service elderly Medicare beneficiaries for whom data existed on OOPEs and Medicare payments. The initial sample was 9,278 HRS respondents aged 65 and older on January 1, 2006, who had been interviewed in 2006 and had consented to providing linked Medicare data. Nine hundred twenty-five respondents who died before the 2008 survey and 280 who were alive in 2008 but did not respond to the 2008 survey were excluded; 436 respondents who had spent at least 30 days in a nursing home during the study period were excluded because nursing home and community-dwelling residents have different patterns of resource use; ${ }^{17} 2,439$ respondents who belonged to a health maintenance organization in 2006 or 2007 or who lacked continuous Part B coverage were excluded because they had incomplete spending information; and 524 respondents insured by a military healthcare plan in 2006 or 2008 were excluded because it was not known what proportion of their care Medicare providers had provided. After excluding 17 people with missing data, the final sample consisted of 4,657 fee-for-service Medicare beneficiaries in 233 HRRs.

\section{Identification of Geographic Cost Quintiles}

HRR-level data from the Institute of Medicine (IOM) on actual 2008 Medicare payments for fee-for-service Medicare beneficiaries aged 65 and older were used to identify spending quintiles. ${ }^{18}$ The 306 HRRs were ranked nationally according to per capita Medicare spending, and then each HRR was placed into a cost quintile. For all fee-for-service Medicare beneficiaries in these HRRs (not just the 4,657 Medicare beneficiaries in the cohort), 2008 per capita Medicare spending averaged \$9,061 $(\$ 7,038$ (lowest quintile), \$7,859, \$8,384, \$9,128, and $\$ 10,955$ (highest quintile)). These cost quintiles were used as exogenous measures of intensity of resource use for the HRS cohort.

To assess whether geographic variation in intensity of resource use for all Medicare beneficiaries in the IOM analysis was associated with variation in Medicare spending by the HRS cohort, each person in the cohort was assigned to an HRR (and thus to one of the cost quintiles described above) based on ZIP code of residence in 2006 (8.4\% of persons had a different ZIP code in 2008, and their mean OOPEs were not statistically different from those who did not move); 2006 and 2007 HRS-linked Medicare claims data (e.g., Medicare Provider Analysis and Review, outpatient, carrier, home health care, hospice, and durable medical equipment files) were then used to obtain per capita Medicare payments for the HRS cohort within each cost quintile.

Medicare payments for the HRS cohort were expected to be lower than those for Medicare beneficiaries in the nation as a whole (than IOM data), because beneficiaries who died between 2006 and 2008 and long-term residents of a nursing home were excluded. These exclusions included 925 decedents and another 436 institutionalized persons who did not die during the study period, together totaling approximately $15 \%$ of the base cohort of 9,278 . Medicare payments for the HRS cohort also did not 
account for annual growth in per enrollee Medicare spending (5\% from 2006 to $2007,6 \%$ from 2007 to 2008$).{ }^{19}$

\section{Definition of Study Outcomes}

The primary outcome was a self-reported measure of OOPEs in the 2 years before the 2008 interview (divided by 2 to annualize it). Estimates for OOPEs came from responses to questions about specific types of healthcare spending (hospital, nursing home, doctor visits, dental care, outpatient surgery, home health care, and special facilities such as outpatient rehabilitation). ${ }^{20}$ For prescription drug spending, respondents are asked about their monthly spending during the previous 2 years; this estimate was multiplied by 12 to produce an annual estimate. The study was focused on exploring OOPEs directly related to healthcare use, so premiums were included only in sensitivity analyses. (The main findings were qualitatively similar; see Appendix 1.)

Out-of-pocket expenditures and the financial burden they place on Medicare beneficiaries were quantified in several ways. In addition to examining mean and median OOPEs, mean OOPEs were estimated as a proportion of household income. The proportion of respondents with nonpremium OOPEs $>5 \%, 10 \%$, and $20 \%$ of income were also examined (and the proportion of respondents with premium plus nonpremium OOPEs $>5 \%, 10 \%$, and $20 \%$ of income in Appendix 1). Prior work has defined premium plus nonpremium OOPEs as burdensome when they exceed $10-20 \%$ of income. ${ }^{9}$

\section{Statistical Analyses}

To answer the first research question (patient factors associated with OOPEs), sociodemographic characteristics associated with OOPEs in the cohort were identified. It was expected that poorer and sicker people would spend a larger proportion of their income on health care. , 10,21,22 $^{2}$ For each characteristic (e.g., age group, sex), differences in mean OOPEs were tested for using analysis of variance. All analyses incorporated HRS's respondent-level weights in 2006 to account for the survey design of the HRS.

Before the main research question was addressed, the sample was stratified according to geographic cost quintile, and the characteristics of the HRS cohort in 2006 were described to compare with prior literature. Differences were tested for using chi-square tests.

To answer the main research question (whether median OOPEs varied across geographic cost quintiles and whether the pattern was similar to Medicare payments), multivariate quantile regression models were run that controlled for the independent variables: age, sex, race and ethnicity, and characteristics in the HRS that might affect OOPEs through mechanisms other than use (net worth in 2006, income in 2006, and supplemental insurance (excluding long-term care insurance) in 2008 or since the 2006 interview). Five separate multivariate models were created, one for each quintile, using only respondents living in each quintile. The entire sample was then used to predict median OOPEs for each person as if they lived in each quintile, so as to keep demographic characteristics the same when making predictions. Unadjusted analyses are also reported in Appendix 1.
Nonparametric bootstrapping with replacement was used to test for the statistical significance of differences in median values for OOPEs (or Medicare payments) in the highest versus lowest cost quintiles. Bootstrapping was also used to assess whether the ratio of Medicare payments between the highest and lowest cost quintiles was significantly different from the ratio of OOPEs between the highest and lowest cost quintiles.

All statistical analyses were conducted using Stata 11.0 (StataCorp, College Station, TX). The University of Michigan Health Sciences and Behavioral Sciences institutional review board approved the HRS, and the institutional review boards at the University of Michigan and Harvard University determined this study to be exempt from ongoing review.

\section{RESULTS}

Median OOPEs were generally higher for those with greater income, wealth, and education and for those in poorer health (Table 1). Median OOPEs were about twice as high in those with more as in those with less education and in those in the highest as in those in the lowest income tertile. In addition, mean OOPEs were approximately $50 \%$ higher in those in fair health than in those in excellent health. OOPEs were more likely to be a financial burden (make up more than $10 \%$ of household income) for nonHispanic blacks and those with less education. Appendix 1 Table S2 contains analogous results for OOPEs including premiums.

In general, few significant differences were found in socioeconomic characteristics across the geographic cost quintiles (Table 2). Although residents of the highest cost quintile tended to be less educated and sicker (consistent with results of a previous study), ${ }^{1}$ these differences were not statistically significant in the current study cohort. Residents of the highest cost quintile were more likely to be non-Hispanic black $(13 \%)$ than residents of the lowest cost quintile $(1 \%)(P=.003)$. Rates of supplemental insurance coverage did not differ across cost quintiles.

In the main empirical results, regional cost quintiles were associated with large differences in Medicare payments, but not with OOPEs (Table 3). In adjusted analyses, median per capita Medicare payments were larger in the highest than in the lowest cost quintiles $(\$ 3,474$ vs $\$ 1,942$, for a ratio of $1.79 ; P<.001$ for difference). Adjusted median OOPEs did not differ between the highest and lowest cost quintiles ( $\$ 795$ vs $\$ 764$, for a ratio of 1.04; $P=.42$ for difference) and did not increase monotonically. The difference between the two ratios (1.79 for median Medicare payments in the highest vs lowest cost quintiles, 1.04 for median OOPEs in the highest vs lowest cost quintiles) was statistically significant $(P<.001)$. For adjusted mean Medicare payments, the Q5:Q1 ratio was $1.48(P<.001)$; for mean OOPEs, the Q5:Q1 ratio was $1.04(P<.001)$. The difference between these two ratios was statistically significant $(P<.001)$. Results were similar in unadjusted analyses and in unadjusted and adjusted sensitivity analyses with premium plus nonpremium OOPEs (Appendix 1 Tables S3 and S4). Unadjusted nonpremium and total (premium plus nonpremium) OOPEs were also examined as a percent of income, but no statistically 
Table 1. Annualized Out-of-Pocket Expenditures (OOPEs) for the Health and Retirement Study Cohort

OOPEs

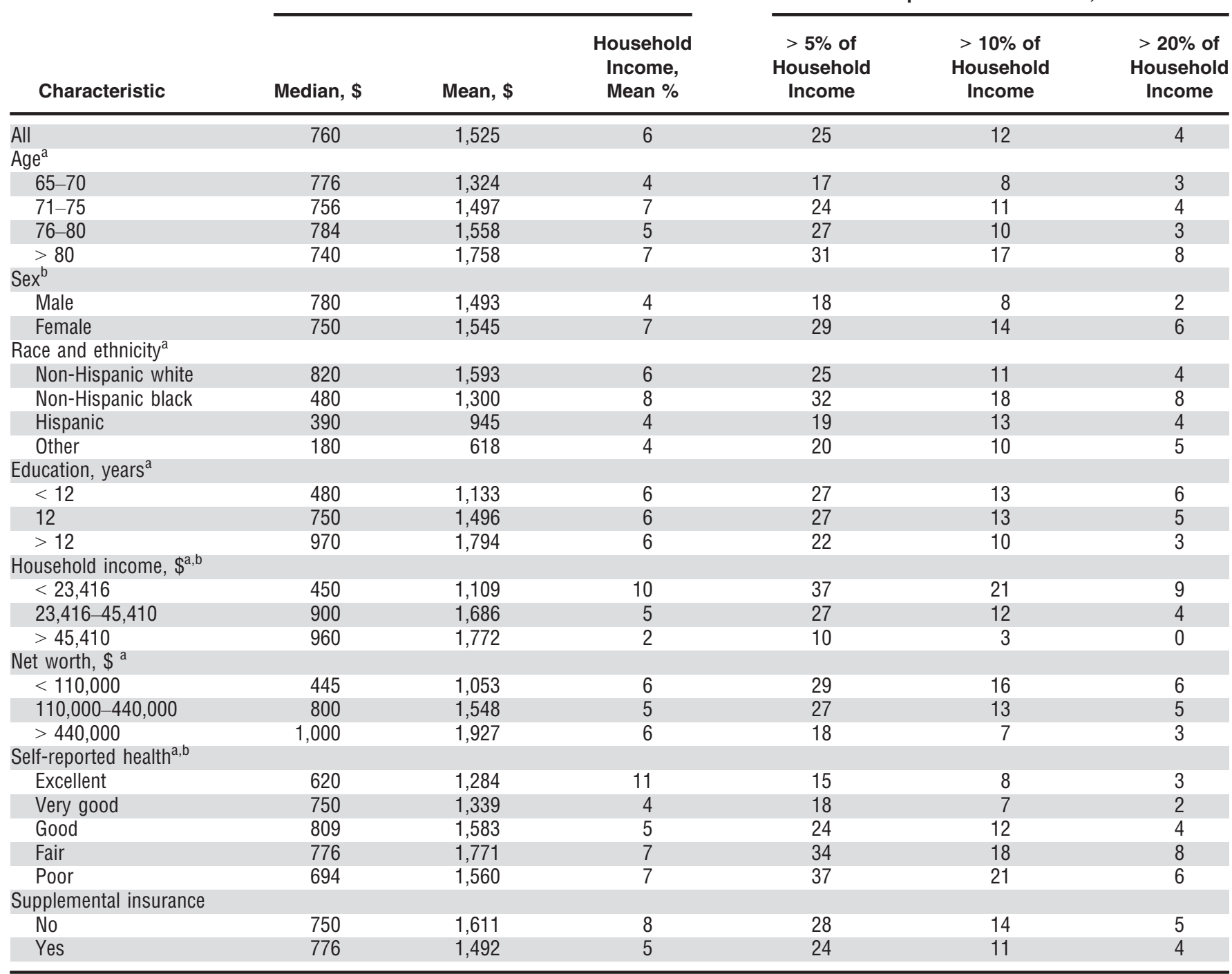

${ }^{\mathrm{a}} \mathrm{P}<.05$ for difference in mean OOPEs.

${ }^{\mathrm{b}} \mathrm{P}<.05$ for difference in mean OOPEs as a percentage of household income.

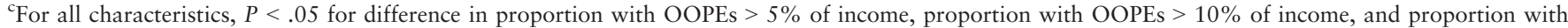
OOPEs $>20 \%$ of income.

significant trend was found across geographic cost quintiles (Figure 1 and Appendix 1 Figure A1). Finally, no statistically significant differences were found in the proportion of people with OOPEs of more than $20 \%$ of income across cost quintiles after adjusting for age, sex, race and ethnicity, supplemental insurance, income, and net worth (results not displayed).

\section{DISCUSSION}

The authors are unaware of previously existing research on the association between geographic variation in healthcare use and patient financial burdens from healthcare costs. The results of the current study document a contrast between geographic variation in cost of care and geographic variation in OOPEs for most Medicare beneficiaries. Adjusted median Medicare payments were $79 \%$ higher in high- than low-cost regions and by design increased monotonically, but adjusted median OOPEs did not follow the same pattern.

Medicare's benefit structure may in part explain the contrast between large geographic variation in Medicare payments and considerably smaller geographic variation in OOPEs (across Medicare cost quintiles). In many instances, Medicare protects beneficiaries from high expenditures. For example, there is a single deductible for hospital care provided during the first 60 days of each benefit period. Thus, OOPEs may be comparable for beneficiaries with a single short hospital stay and those with several prolonged hospitalizations. In contrast, Medicare payments would vary widely between these two scenarios.

The broad prevalence of other types of insurance, including employer sponsored insurance, Medigap, and Medicaid, may also explain the current study's findings. 
Table 2. Characteristics of the Health and Retirement Study Cohort According to Regional Cost Quintile

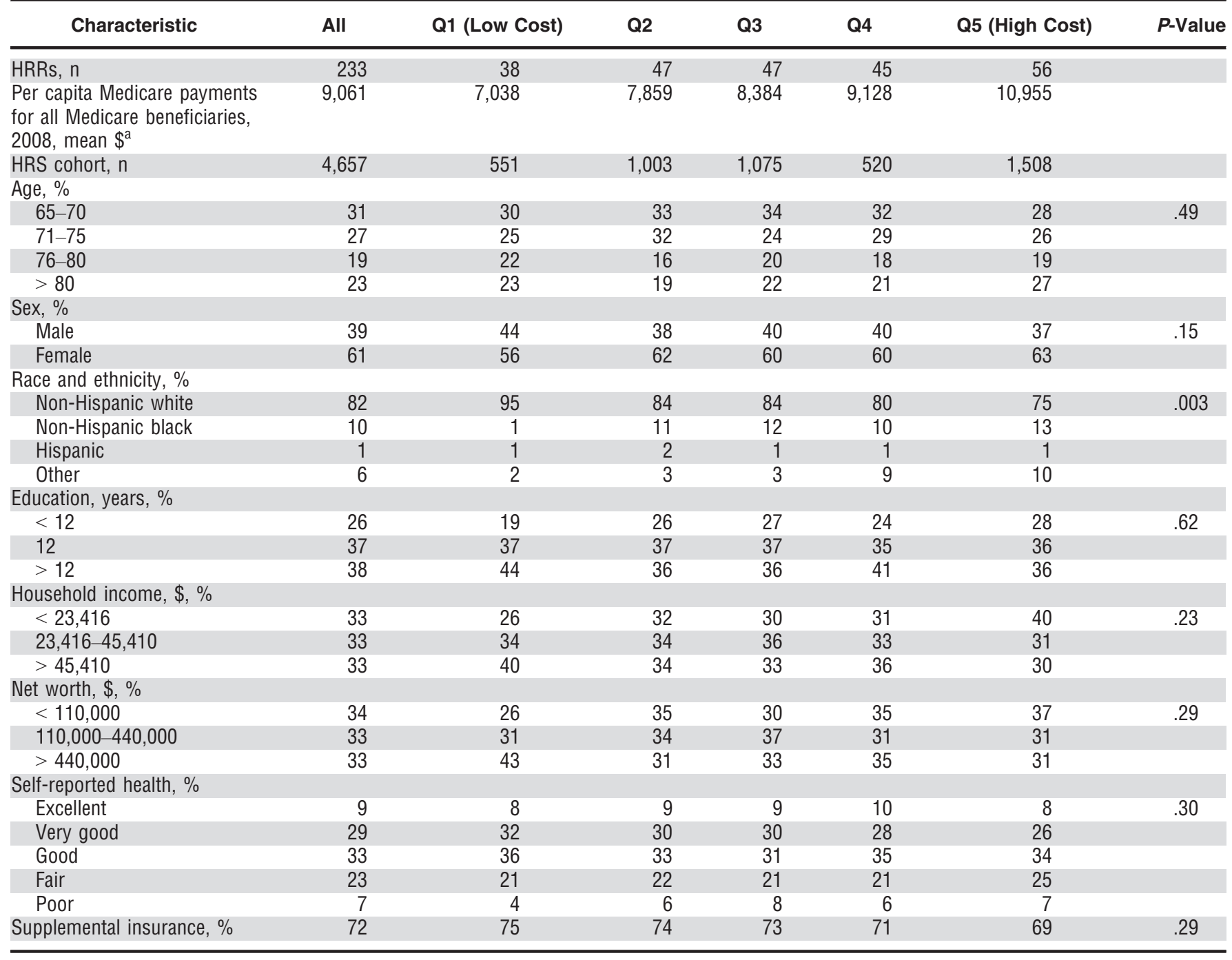

${ }^{a}$ From the Institute of Medicine's Hospital Referral Region (HRR)-level data on actual 2008 Medicare payments for fee-for-service Medicare beneficiaries aged 65 and older enrolled in Part A and B.

Table 3. Adjusted $^{\mathrm{a}}$ Annualized Medicare Payments and Out-of-Pocket Expenditures (OOPEs) for the Health and Retirement Study Cohort According to Geographic Cost Quintile

\begin{tabular}{|c|c|c|c|c|c|c|c|c|}
\hline \multirow{2}{*}{$\begin{array}{c}\text { Type of } \\
\text { Expenditure }\end{array}$} & \multicolumn{6}{|c|}{ Cost Quintile, \$ } & \multirow[b]{2}{*}{ Q5:Q1 } & \multirow{2}{*}{$\begin{array}{c}P \text {-Value } \\
\text { (Q5 vs Q1) }\end{array}$} \\
\hline & All & Q1 (Low Cost) & Q2 & Q3 & Q4 & Q5 (High Cost) & & \\
\hline \multicolumn{9}{|c|}{ Medicare payments ${ }^{b}$} \\
\hline Median & 2,635 & 1,942 & 2,515 & 2,575 & 2,805 & 3,474 & 1.79 & $<.001$ \\
\hline Mean & 5,916 & 4,546 & 5,586 & 5,996 & 5,283 & 6,731 & 1.48 & $<.001$ \\
\hline \multicolumn{9}{|l|}{ OPPEs } \\
\hline
\end{tabular}

${ }^{a}$ Adjusted for age, sex, race and ethnicity, net worth in 2006, income in 2006, and supplemental insurance (excluding long-term care insurance) in 2008 or since the 2006 interview. Cost quintile is based on Medicare payments for fee-for-service Medicare beneficiaries aged 65 and older.

${ }^{b}$ From HRS-linked Medicare claims data for the HRS cohort.

Approximately $72 \%$ of this HRS sample was covered by supplemental insurance. The effect of supplemental insurance on OOPEs can be difficult to extract precisely because of potential endogeneity; individuals expecting higher use are more likely to buy supplemental insurance. $^{23}$

Results from this study complement prior research on OOPEs of Medicare beneficiaries. ${ }^{9,17,24-29}$ For example, 


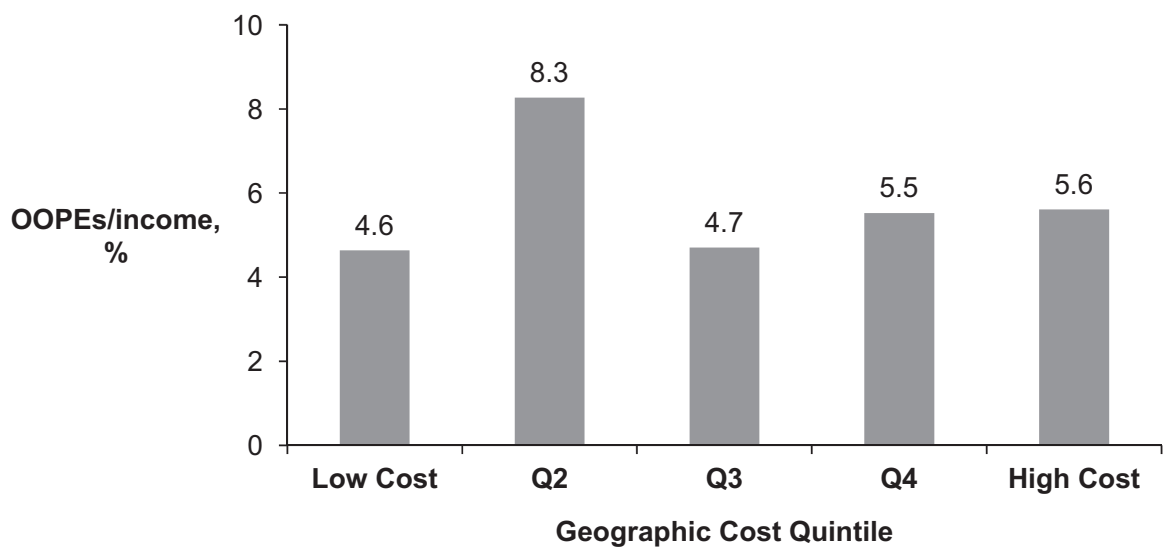

Figure 1. Unadjusted mean out-of-pocket expenditures (OOPEs)/income according to geographic cost quintile. $P=.68$ for trend. Cost quintile is based on Medicare payments for fee-for-service Medicare beneficiaries aged 65 and older.

the findings of higher OOPEs in non-Hispanic whites and those with higher income or worse health are consistent with previous work that relied on OOPEs as reported in the Medicare Current Beneficiary Survey (MCBS). ${ }^{9}$ Nevertheless, none of these studies examined the association between geographic variation in costs of care and OOPEs.

The current study has several important limitations. First, the results and their implications are not generalizable to all older Americans, because the cohort was limited to community-dwelling, noninstitutionalized Medicare beneficiaries with fee-for-service coverage. Individuals who died between 2006 and 2008 and those who were institutionalized were excluded. In a 2-year sample, these two excluded groups would comprise approximately $15 \%$ of the population of older Americans. Second, OOPEs are self-reported in the HRS, but HRS data on OOPEs have been used in prior research, and they are comparable with data from the MCBS and the Medical Expenditure Panel Survey. ${ }^{26,30}$ Third, total nonpremium OOPEs and geographic variation in total Medicare payments were examined; it is possible that individual components of OOPEs, such as prescription drug spending, are weakly associated with geographic variation specific to certain types of expenditures (e.g., Part D spending). Fourth, $72 \%$ of the HRS sample had supplementary insurance, whereas prior reports of MCBS have cited that approximately $90 \%$ of noninstitutionalized fee-for-service Medicare beneficiaries have such coverage. $^{31}$ The reason for this difference could not be identified, but there is no reason why HRS data should be less accurate. ${ }^{32}$ Fifth, information was not available on levels of supplemental insurance, which vary. During the study time frame, almost two-thirds of Medicare beneficiaries with Medigap chose two supplemental insurance plans with very generous coverage. ${ }^{33}$ Finally, with the study data, not all of the factors that might modify the association between geographic cost quintiles and OOPEs could be controlled for, which may explain in part why the results for OOPEs were not monotonic.

In summary, consistent with prior studies, wide geographic variation was found in Medicare payments. In contrast, OOPEs varied much less across Medicare cost quintiles. It is plausible that Medicare's benefit structure and the prevalence of generous supplemental insurance coverage provides a leveling in OOPEs for many Americans, but the concomitant challenge is that protection against higher OOPEs also reduces the incentive that older Americans have to limit healthcare use or to support policies that aim to do so.

\section{ACKNOWLEDGMENTS}

We thank Mary Jane Giesey, BA, and Natalie J. Lin, BA, for their research assistance. Ms. Giesey and Ms. Lin were compensated for their work.

Conflict of Interest: The editor in chief has reviewed the conflict of interest checklist that the authors provided and has determined that the authors have no financial or any other kind of personal conflicts with this paper.

Author Contributions: Dr. Chen had full access to all of the data in the study and takes responsibility for the integrity of the data and the accuracy of the data analysis. Study concept and design: Chen, Epstein. Acquisition of data: Chen, Langa. Drafting of the manuscript: Chen. Revision of the manuscript for important intellectual content: Chen, Norton, Langa, Le, Epstein. Statistical analysis: Chen, Norton, Le, Epstein. Administrative, technical or material support: Epstein. Study supervision: Epstein.

Sponsor's Role: Dr. Chen is supported by Career Development Grant K08HS020671 from the Agency for Healthcare Research and Quality. This material is the result of work supported with resources of the Health Services Research and Development Center of Excellence, Veterans Affairs Ann Arbor Healthcare System, Ann Arbor, Michigan.

\section{REFERENCES}

1. Fisher ES, Wennberg DE, Stukel TA et al. The implications of regional variations in Medicare spending. Part 1: The content, quality, and accessibility of care. Ann Intern Med 2003a;138:273-287.

2. Fisher ES, Wennberg DE, Stukel TA et al. The implications of regional variations in Medicare spending. Part 2: Health outcomes and satisfaction with care. Ann Intern Med 2003b;138:288-298.

3. Institute of Medicine. New Data on Geographic Variation [on-line]. Available at http://iom.edu/Activities/HealthServices/GeographicVariation/ Data-Resources.aspx Accessed February 12, 2012.

4. Wennberg JE, Bronner K, Skinner JS et al. Inpatient care intensity and patients' ratings of their hospital experiences. Health Aff (Millwood) 2009;28:103-112. 
5. Barnato AE, Chang CC, Farrell $\mathrm{MH}$ et al. Is survival better at hospitals with higher "end-of-life" treatment intensity? Med Care 2010;48:125-132.

6. Landrum MB, Meara ER, Chandra A et al. Is spending more always wasteful? The appropriateness of care and outcomes among colorectal cancer patients. Health Aff (Millwood) 2008;27:159-168.

7. Ong MK, Mangione CM, Romano PS et al. Looking forward, looking back: Assessing variations in hospital resource use and outcomes for elderly patients with heart failure. Circ Cardiovasc Qual Outcomes 2009;2:548-557.

8. Himmelstein DU, Thorne D, Warren E et al. Medical bankruptcy in the United States, 2007: Results of a national study. Am J Med 2009;122:741-746.

9. Neuman P, Cubanski J, Desmond KA et al. How much 'skin in the game' do Medicare beneficiaries have? The increasing financial burden of health care spending, 1997-2003. Health Aff (Millwood) 2007;26:1692-1701.

10. Banthin JS, Bernard DM. Changes in financial burdens for health care: National estimates for the population younger than 65 years, 1996 to 2003. JAMA 2006;296:2712-2719.

11. Cunningham PJ. Trade-offs getting tougher: Problems paying medical bills increase for U.S. families, 2003-2007. Track Rep 2008;21:1-5.

12. Doty MM, Collins SR, Rustgi SD et al. Seeing red: The growing burden of medical bills and debt faced by U.S. families. Issue Brief (Commonw Fund) 2008;42:1-12.

13. Hogan C. Exploring the effects of secondary coverage on Medicare spending for the elderly, 2009 [on-line]. Available at http://www.naic.org/documents/committees_b_senior_issues_110628_hogan.pdf Accessed January 22, 2014.

14. Golberstein E, Walsh K, He Y et al. Supplemental coverage associated with more rapid spending growth for Medicare beneficiaries. Health Aff (Millwood) 2013;32:873-881.

15. Cassidy A. Health Affairs Health Policy Brief: Putting limits on 'Medigap,' 2011 [on-line]. Available at http://www.healthaffairs.org/healthpolicybriefs/ brief_pdfs/healthpolicybrief_52.pdf Accessed January 22, 2014.

16. Health and Retirement Study. Sample Sizes and Response Rates 2011 [on-line]. Available at http://hrsonline.isr.umich.edu/sitedocs/sampleresponse.pdf Accessed September 10, 2012.

17. Kaye HS, Harrington C, LaPlante MP. Long-term care: Who gets it, who provides it, who pays, and how much? Health Aff (Millwood) 2010;29:1121.

18. Institute of Medicine (IOM). Geographic Variation Data Request: A Methodological Overview, December 2011 Update [on-line]. Available at http://iom.edu/Activities/HealthServices/GeographicVariation/ /media/ Files/Activity \%20Files/HealthServices/GeographicVariation/CMS $\% 20$ Files $\%$ 2012-8-Geographic\%20Variation \%20Methods\%20Paper\%20\%20IOM\% 20Data\%20December\%202011\%20Update.pdf Accessed September 10, 2012.

19. National Health Expenditures Accounts. NHE Tables [on-line]. Available at Statistics-Data-and-Systems/Statistics-Trends-and-Reports/NationalHealthExpendData/Downloads/tables.pdf Accessed July 16, 2012.

20. St. Clair P, Blake D, Bugliari D et al. RAND HRS Data Documentation, Version K: Labor \& Population Program, RAND Center for the Study of Aging, 2011 [on-line]. Available at http://www.rand.org/labor/aging/dataprod/hrs-data.html Accessed March 25, 2014.

21. Banthin JS, Cunningham P, Bernard DM. Financial burden of health care, 2001-2004. Health Aff (Millwood) 2008;27:188-195.

22. Crystal S, Johnson RW, Harman J et al. Out-of-pocket health care costs among older Americans. J Gerontol B Psychol Sci Soc Sci 2000;55B:S51S62.

23. Medicare Payment Advisory Commission. Report to the Congress: Medicare and the Health Care Delivery System, 2012 [on-line]. Available at http://www.medpac.gov/documents/Jun12_EntireReport.pdf Accessed July $8,2012$.

24. Gruber J, Levy H. The evolution of medical spending risk. J Econ Perspect 2009;23:25-48.

25. Neuman T, Cubanski J, Desmond K et al. How much "skin in the game" is enough? The Henry J. Kaiser Family Foundation, June 2011 [on-line]. Available at http://www.kff.org/medicare/upload/8170.pdf Accessed July 8, 2012.

26. Goldman DP, Zissimopoulos JM. High out-of-pocket health care spending by the elderly. Health Aff (Millwood) 2003;22:194-202.

27. Langa KM, Fendrick AM, Chernew ME et al. Out-of-pocket health-care expenditures among older Americans with cancer. Value Health 2004a;7:186-194.

28. Langa KM, Larson EB, Wallace RB et al. Out-of-pocket health care expenditures among older Americans with dementia. Alzheimer Dis Assoc Disord 2004b;18:90-98.
29. Riley GF. Trends in out-of-pocket healthcare costs among older community-dwelling Medicare beneficiaries. Am J Manag Care 2008;14:692-696.

30. Goldman DP, Zissimopoulos J, Yang L. Medical Expenditure Measures in the Health and Retirement Study. Forum for Health Economics \& Policy 2011 [on-line]. Available at http://www.ncbi.nlm.nih.gov/pubmed/ 24049512 Accessed April 21, 2014.

31. Medicare Payment Advisory Commission. A Data Book: Health Care Spending and the Medicare Program, 2012 [on-line]. Available at http://medpac. gov/documents/Jun12DataBookEntireReport.pdf Accessed July 24, 2012.

32. Levy H, Gutierrez I. Documentation and Benchmarking of Health Insurance Measures in the Health and Retirement Study, 2009 [on-line]. Available at http://hrsonline.isr.umich.edu/sitedocs/userg/HRS_HealthInsuranceMeasures.pdf Accessed January 13, 2014.

33. America's Health Insurance Plans. Characteristics of Medigap Policies, December 2009, 2010 [on-line]. Available at http://www.ahipresearch.org/ pdfs/Medigap2009.pdf Accessed January 22, 2014.

\section{APPENDIX 1}

To complete sensitivity analyses that used premium plus nonpremium out-of-pocket expenditures (OOPEs), premiums were estimated in the following way. The Health and Retirement Study (HRS) includes a series of questions about enrollment in private insurance plans (excluding long-term care insurance, Part D insurance, Medicaid and Medicare health maintenance organizations, Veterans Affairs insurance, and Medicaid), and self-reported premiums for such plans. In the current study sample, 3,057 $(66 \%)$ had at least one additional private insurance plan. Because only $167(4 \%)$ in the cohort had more than one private insurance plan, premiums were included for the first additional private insurance plan only. If the first additional private insurance plan also covered a respondent's spouse, the premium was divided by two to obtain an individual estimate. To this, Medicare Part B premiums from publicly available rates for 2007 were added. Because most Medicare beneficiaries do not pay for Part A and because monthly premiums for Part D were small (national average of approximately $\$ 26$ per month in 2006) (Neuman P and Cubanski J, NEJM, 2009), these values were not included in the premium estimates.

HRS respondents self-report exact monthly premium amounts and, if unable to do this, provide the upper and lower bounds for premium estimates. For HRS respondents without an additional insurance plan in 2008, the premium value was set to zero. For those who reported a monthly premium of a reasonable upper bound of $\$ 300$ or less (the upper limit for monthly Medigap premiums found at www.medicare.gov), that value was used. If the exact 2008 premium provided was more than $\$ 300$, the 2006 premium was used (if it was $\leq \$ 300$ ). Otherwise, the value was imputed using a model in which premium was regressed on race, sex, age, self-reported health status, and census region.

For respondents who did not provide an exact premium but confirmed that their premium was within a range of values, an exact amount was imputed. If the lower limit of the range provided was $\$ 300$ or less, we estimated the premium as that value midway between the lower and upper limit (fixing the maximum upper limit at $\$ 300$ ). If the lower limit of the range provided was $>\$ 300$, data from 2006 were examined. If an exact premium $<\$ 300$ had been reported in 2006, that amount was used. Otherwise, the premium was imputed using the regression model described above. 
In the cohort, 1,568 (34\%) had no additional insurance plan and a premium of zero (Table S1). Another $2,442(52 \%)$ had a premium of $\$ 300$ or less. Another 270 $(6 \%)$ stated that the lower bound of their premium payment was $<\$ 300$, and the value between the lower and upper bounds was picked to estimate an exact premium. For 182 respondents $(4 \%)$, exact premium values provided in 2006 were used. For the remainder $(195,4 \%)$, premiums were imputed using the regression model described above.

\section{SUPPORTING INFORMATION}

Additional Supporting Information may be found in the online version of this article:

Table S1. Premium Imputations for First Additional Insurance Plan.
Table S2. Annualized Out-of-Pocket Expenditures with Premiums, by Cohort Characteristics.

Table S3. Unadjusted Annualized Medicare Payments and Non-Premium OOPEs for the HRS Cohort, by Geographic Cost Quintile.

Table S4. Annualized Medicare Payments and OOPEs including Premiums for HRS Cohort, by Geographic Cost Quintile.

Figure S1. Unadjusted Mean Total (Premium plus Non-Premium) Out-of-Pocket Expenditures/Income, by Geographic Cost Quintile.

Please note: Wiley-Blackwell is not responsible for the content, accuracy, errors, or functionality of any supporting materials supplied by the authors. Any queries (other than missing material) should be directed to the corresponding author for the article. 